\title{
Purification and characterization of a carboxylesterase involved in malathion-specific resistance from Tribolium castaneum (Coleoptera: Tenebrionidae)
}

\author{
Eric Haubruge ${ }^{a}$, Marcel Amichot ${ }^{\mathrm{b}}$, André Cuany ${ }^{\mathrm{b}}$, Jean-Baptiste Berge ${ }^{\mathrm{b}}$, Ludovic Arnaud ${ }^{\mathrm{a}}$ \\ a Department of Pure and Applied Zoology, Gembloux Agricultural University, B-5030 Gembloux, Belgium \\ ${ }^{\mathrm{b}}$ Laboratoire de Biologie des Inverte'bre's, INRA, Centre d'Antibes, BP 2078, 06606 Antibes, Cedex, France
}

\begin{abstract}
Specific resistance to malathion in a strain of Tribolium castaneum is due to a 44-fold increase in malathion carboxylesterase (MCE) activity relative to a susceptible strain, whereas non-specific esterase levels are slightly lower. Unlike the overproduced esterase of some mosquito and aphid species, MCE in Tribolium castaneum accounts for only a small fraction $(0.033-0.045 \%)$ of the total extractable protein respectively in resistant and susceptible strains. The enzyme was purified to apparent homogeneity from these two strains and has a similar molecular weight of 62,000. However, preparative isoelectricfocusing indicated that resistant insects possess one MCE with $\mathrm{p} I$ of 7.3, while susceptible insects possess a MCE with a $\mathrm{p} I$ of 6.6. Purified MCE from both populations had different $K_{m}$ and $V_{\mathrm{m}}$ values for hydrolysis of malathion as well as for $\alpha$-naphthyl acetate. The kinetic analysis suggests that MCE of resistant insects hydrolyses malathion faster than the purified carboxylesterase from susceptible beetles and that this enzyme has greater affinity for malathion than for naphthyl esters. Malathion-specific resistance is due to the presence of a qualitatively different esterase in the resistant strain.
\end{abstract}

\begin{abstract}
Abbreviations: AChE, acetylcholinesterase; ADH, alcohol dehydro-genase; DTT, dithiothreitol; INT, piodonitrophenyl tetrazolium violet; MCE, malathion carboxylesterase; NAD, adenosine dinucleotide; NSE, nonspecific esterase; PAGE, polyacrylamide gel electrophoresis; SDS, sodium dodecyl sulfate
\end{abstract}

\section{Introduction}

As a consequence of the intensive use of malathion in grain storage, the first case of malathion-resistance in Tribolium castaneum was reported in 1961. Ten years later, this phenomenon was regarded as a common attribute of this species (Champ and Dyte, 1976). Moreover, the malathion-specific resistant phenotype in T. castaneum populations, has almost completely replaced the susceptible one (Beeman and Nanis, 1986).

In T. castaneum, two types of malathion resistance occur which are referred to as malathion-specific and malathion non-specific. The first type confers a cross resistance to close analogues of malathion and is completely overcome by the synergist triphenyl phosphate (TPP). The second type involves cross resistance to many insecticides and insect hormones. This resistance could be synergised by the mixed function oxidase inhibitor SKF 525A (Walter and Price, 1989). The mala-thion-specific resistance mechanism controls most or the whole field resistance in $T$. castaneum and is very stable in field populations, even when insecticide exposure is discontinued (Beeman and Nanis, 1986).

In malathion-specific resistant strains of $T$. castaneum, malathion can be degraded by a carboxylesterase to less toxic more easily excreted carboxylic acids (Dyte and Rowlands, 1968; Price, 1984). The malathion-specific resistance is always accompanied by reduced $\alpha$-naphthyl acetate esterase activity in resistant strains of the red flour beetle T. castaneum (Wool et al., 1982; Mackness et al., 1983). The increased MCE activity can arise through a qualitative change such that the esterase's rate of hydrolysis of malathion increases (Price, 1984).

Recent works with Lucillia cuprina (Whyard et al., 1994a), Culex tarsalis (Whyard et al., 1995), Cryptolestes ferrugineus (Spencer et al., 1998) and Anisoptero-malus calandrae (Baker et al., 1998) suggest that mala-thion resistance could be due to the presence of a qualitatively different esterase in the resistant strain.

This paper describes the isolation and the kinetic characterization of a carboxylesterase from a susceptible and a resistant strain of $T$. castaneum in order to determine the biochemical mechanism of the specific type resistance.

\section{Experimental procedures}




\subsection{Insects}

Two flour beetle strains were used in this study. One strain specifically resistant to malathion called " $P R m$ ", was originally collected from a grain store in the Phillip-ines. The second strain " $A s m$ " susceptible to malathion, was collected from storage facilities in Abidjan (Ivory Coast). The insects were reared with whole wheat flour enriched with brewer's yeast $(10 / 1 \mathrm{w} / \mathrm{w})$ and kept in the dark at $30 \pm 3^{\circ} \mathrm{C}$ and $65 \pm 5 \%$ relative humidity (r.h.) (Haubruge et al., 1997).

\subsection{Chemicals}

Non-labelled analytical grade insecticides were obtained from Riedel de Haan Ag.; $\left[{ }^{14} \mathrm{C}\right]$ Malathion (103 $\mathrm{mCi} / \mathrm{mmol}$; labelled on the succinyl carbons) came from Amersham; malathion metabolites were prepared as derscribed by Matthews (1980) after the method of March et al. (1956). Biochemicals were purchased from Boerhinger Manheim, Sigma Chemical Co., Pharmacia LKBand BioRad. All chemicals and buffers were of reagent grade or better.

\subsection{Insecticide bioassays and synergist studies}

Adult beetles (2-4 weeks old) were tested for toxicity of various insecticides using an insecticide contact method. All insecticides were analytical grade unless otherwise indicated. One hundred adults were exposed for $24 \mathrm{~h}$ to a filter paper impregnated with an acetonic solution of insecticide; 7 concentrations were used for susceptible beetles and 9 for resistant beetles. Controls were treated with acetone alone. Afterwards, the number of dead adults were observed. We considered adults dead when they were motionless or exhibited completely uncoordinated movements. Enzyme inhibitors were tested for their ability to synergize the toxic effect of malathion in resistant insects in vivo. Adults were exposed to various concentrations of malathion in the presence of a non-lethal concentration (ratio=1:5) of one of the three inhibitors: the carboxylesterase inhibitor, tri-phenylphosphate; the polysubstrate monooxygenase inhibitor, pyperonyl butoxide and the glutathione Stransferase inhibitor, diethyl maleate. Mortality was determined $24 \mathrm{~h}$ later and compared to controls which were treated with malathion alone. Mortality data were pooled for Probit analysis (Raymond, 1993).

\subsection{Homogenate preparation}

One- to five-day-old adults were mass-homogenised with a teflon-glass homogenizer at $4^{\circ} \mathrm{C}$ in $10 \mathrm{mM}$ phosphate buffer $\mathrm{pH}$ 6.8. The homogenates were filtered through glass wool and centrifuged at $2000 \mathrm{~g}$ for $15 \mathrm{~min}$. The resulting supernatants and pellets were used for enzymatic assays, PAGE electrophoresis or to isolate subcellular fractions.

For the study of the developmental pattern of NSE and MCE activities, 2-day-old eggs (100 mg), 9-10-day-old larvae (10 individuals), 2-day-old pupae (10 individuals) and 8-day-old adults (5 individuals) were used. The homogenates were prepared using the same homogenisation medium (10 mM phosphate buffer $\mathrm{pH} 6.8)$ and were centrifuged at $14,000 \mathrm{~g}$ for $15 \mathrm{~min}$. The cytosolic fractions were then used for NSE and MCE assays.

\subsection{Subcellular localization}

To obtain subcellular fractions, the $2000 \mathrm{~g}$ supernatant was spun at $15,000 \mathrm{~g}$ for $15 \mathrm{~min}$; the pellet was resuspended and spun at $15,000 \mathrm{~g}$. The mitochondrial pellet was then resuspended in the same volume as the initial $2000 \mathrm{~g}$ supernatant. The first and wash supernatant from the $15,000 \mathrm{~g}$ spin were mixed and centrifuged at $100,000 \mathrm{~g}$ for $60 \mathrm{~min}$. The microsomal pellet was rinsed with phosphate buffer and resuspended in homogenizing phosphate buffer combining 1\% Triton X-100. The 100,000 $g$ supernatant corresponded to the cytosolic fraction. Non-specific esterase (NSE) and MCE activity were assayed three times in each fraction.

\subsection{Enzyme assays}

\subsubsection{NSE}

During purification, esterase activity was assayed at $527 \mathrm{~nm}$ by using $\alpha$-naphthyl acetate in $10 \mathrm{mM}$-phos-phate buffer pH 6.9 at $25^{\circ} \mathrm{C} .70 \mu \mathrm{l}$ of $\alpha$-naphthyl acetate $(0.2 \mathrm{mM})$ were added to $6.23 \mathrm{ml}$ of $\mathrm{PB}$ and $800 \mu \mathrm{l}$ of this mixture were placed in a $1.5 \mathrm{ml}$-cuvette. After $15 \mathrm{~min}$, the reaction was stopped by adding $100 \mu 1$ of the staining solution (150 mg Fast Garnett GBC in $50 \mathrm{ml}$ of 5\% SDS). Absorbance was read at $527 \mathrm{~nm}$ on a spectrophotometer Shimadzu 160 A. 


\subsection{2. $M C E$}

$195 \mu \mathrm{l}$ of extract were added to $5 \mu \mathrm{l}$ of ethanol solution containing $\left[{ }^{14} \mathrm{C}\right]$ malathion $(50 \mathrm{nCi})$ and $500 \mathrm{ng}$ of unlabeled malathion; the assay mixtures were incubated for $60 \mathrm{~min}$. After $1 \mathrm{~h}$, malathion was extracted three times with $1000 \mu \mathrm{l}$ of chloroform. The acid metabolites remaining in the aqueous phase were determined by liquid scintillation counting (Beckmann, 6050).

\subsection{Protein determination}

The protein concentration of homogenates was determined by the method of Lowry et al. (1951). Serial dilutions of bovine serum albumin were used for the construction of a standard curve that provided the extinction coefficient.

\subsection{Purification of $M C E$}

The $100,000 \mathrm{~g}$ supernatant was fractionated by ammonium sulphate precipitation. The $55-80 \%$ precipitate were resuspended and dialysed for $24 \mathrm{~h}$ against three changes of $10 \mathrm{mM}$ Tris- $\mathrm{HCl}$ buffer $\mathrm{pH} 8$. The dialysed solution was filtrated on a Sephadex G-200 column $(2.6 \times 90 \mathrm{~cm})$ equilibrated with $10 \mathrm{mM}$ Tris-HCl buffer $\mathrm{pH} 8$. The MCE peak fractions were mixed and loaded on a DEAE-650 Fractogel equilibrated with $10 \mathrm{mM}$ Tris-HCl buffer $\mathrm{pH}$ 8. One peak fraction (MCE) was collected directly without $\mathrm{NaCl}$. Another peak fraction (NSE) was collected by elution with $1 \mathrm{M} \mathrm{NaCl}$. The MCE peak fraction was dialyzed for $24 \mathrm{~h}$ against three changes of $10 \mathrm{mM}$ phosphate buffer $\mathrm{pH}$ 6.8. The dialyzed fraction was loaded onto a Biogel HTP hydrox-yapatite column previously equilibrated with $10 \mathrm{mM}$ phosphate buffer $\mathrm{pH}$ 6.8. The MCE peak fraction was eluted with $400 \mathrm{mM}$ phosphate buffer $\mathrm{pH}$ 6.8. The enzyme fraction was dialyzed for $24 \mathrm{~h}$ against two changes of $10 \mathrm{mM}$ phosphate buffer $\mathrm{pH} 6.8$ and lyophilised.

The partially purified MCE peak fraction was resuspended in a $50 \mathrm{ml}$ solution of bidistilled water containing 750 $\mu \mathrm{l}$ of ampholine carrier ampholytes (Biolyte 3.5-9.5; Bio Rad, Richmond, CA). This solution was poured into a Rotofor migration cell. Solutions of anolyte and catholyte were respectively $\mathrm{NaOH}(0.1 \mathrm{M})$ and $\mathrm{H}_{3} \mathrm{PO}_{4}(0.1 \mathrm{M})$. Isoelectric focusing was performed with a Rotofor Preparative IEF Cell (Bio Rad, Richmond, CA) at $12 \mathrm{~W}$ constant power during $4 \mathrm{~h}$ at $4^{\circ} \mathrm{C}$. The MCE peak fraction was collected and dialyzed for $24 \mathrm{~h}$ against two changes of $10 \mathrm{mM}$ phosphate buffer $\mathrm{pH} 6.8$.

Continuous native polyacrylamide electrophoresis was performed in a Prep-Cell model 491 (Bio-Rad, Hercules, CA). The dialyzed sample, after elution from preparative isofocalisation, was mixed with glycerol (final concentration of $10 \%$ ) and bromophenol blue (final concentration of $0.025 \%$ ). The sample, approximately $1 \mathrm{mg}$ of protein, was loaded on a $8 \% \mathrm{~T} / 3 \% \mathrm{C}, 10 \mathrm{~cm}$ PAGE. Electrophoresis was performed at $20 \mathrm{~W}$ constant power $(250 \mathrm{~V})$. When the first protein band had just run off the gel, the voltage was increased to $350 \mathrm{~V}$. The elution $(0.5 \mathrm{ml} / \mathrm{min})$ and fraction collection $(5 \mathrm{ml})$ were begun.

\subsection{Denaturing polyacrylamide gel electrophoresis}

For visualisation of the protein content of crude enzyme homogenates and column fractions during the purification procedure, aliquots of peak fractions were diluted $1: 4$ with a solubilizer (1\% SDS; $0.02 \%$ bromophenol; $1 \% \mathrm{P}$-mercaptoethanol in running buffer) and boiled for $3 \mathrm{~min}$ before electrophoresis. Separation gels were $10 \%$ acrylamide $/ 0.01 \%$ SDS in $0.5 \mathrm{M}$ Tris-HCl $\mathrm{pH} 8.8$. Stacking gel was $3.5 \%$ of acrylamide in $1.5 \mathrm{M}$ Tris-HCl pH 6.8. The Laemmli discontinuous buffer system was used; 10x running buffer is $2 \mathrm{M}$-glycine $/ 0.1 \%$ $\mathrm{SDS} / 0.4 \mathrm{M}$ Tris, $\mathrm{pH}$ 8.3. Electrophoresis was carried out at $45 \mathrm{~V}$ and $20 \mathrm{~mA}$ overnight in a Hoeffer vertical electrophoresis.

\subsection{Gel filtration}

After purification steps, the molecular weight of MCE from resistant and susceptible T. castaneum strains were determined using a Sephacryl S-200 HR column $(16 \times 400 \mathrm{~mm})$ equilibrated with $10 \mathrm{mM}$ Tris-HCl buffer pH 8. The column was calibrated at $4^{\circ} \mathrm{C}$ using Blue Dex-tran and standard proteins (Mr, 12,400-200,000). Purified MCE sample $(1 \mathrm{ml})$ was applied to the column and eluted at $0.05 \mathrm{ml} / \mathrm{min}$ flow rate.

\subsection{1. pI determination}

Analytical IEF was performed in a Rotofor apparatus using ampholine carrier ampholytes (Biolyte 3.5-9.5; Bio 
Rad, Richmond, CA). The focusing parameters were identical to those of preparative isoelectricfocusing. The $\mathrm{pH}$ gradient was determined by measuring the $\mathrm{pH}$ of the solution using a PHM92 $\mathrm{pH}$ meter (Radiometer, Copenhagen), standardized with a buffer of known pH (Fischer Certified Buffer) before each reading.

\subsection{Kinetic analysis}

Enzyme kinetics of the purified MCE from resistant and susceptible T. castaneum strains was determined by recording the activity toward nine concentrations (1-500 $\mu \mathrm{M})$ of $\alpha$-naphthyl acetate and six concentrations $(\mu \mathrm{M})$ of malathion. Maximal velocity $V_{m}$ and Michaelis constant $K_{m}$ values for both the substrates were determined from Lineweaver-Burk plots. The turnover number $\left(k_{\text {cat }}\right)$ was calculated according to the molecular weight of purified MCE and $V_{\text {max }}$. The substrate specificity constant $\left(k_{c a t} / K_{m}\right)$ was determined based on $k_{c a t}$ and $K_{m}$.

\section{Results}

\subsection{Malathion toxicity and synergist studies}

Probit analysis results are shown in Table 1. Resistance was of the malathion-specific type. The PRm strain was 250-fold more resistant to malathion than the $A s m$ strain at the $\mathrm{LC}_{50}$ level. The resistant strain had little or no cross-resistance to chemically unrelated insecticide ester such as deltamethrin and only 1.8 -fold cross-resistance to pirimiphos-methyl. There was a low order of cross-resistance to malaoxon (the active analogue of malathion).

Malathion resistance in the resistant strain was sup-ressed by treatment of insects with the non-toxic carboxylesterase inhibitor triphenyl phosphate (TPP).

\subsection{Esterase activities and subcellular localization}

The developmental profile of malathion carboxylester-ase (MCE) and non-specific esterase in both strains (PRm and Asm) was determined at different times after oviposition. MCE and NSE were present in all stages of development from eggs to adults (Fig. 1). In the resistant strain, specific activity of MCE was high in adults, and in the susceptible strain the larval stage had the highest NSE activity.

The $P R m$ resistant strain showed lower esterase activity toward $\alpha$-naphthyl acetate than the susceptible strain Asm (Table 2). But the ratio of MCE between the resistant and the susceptible strains is more elevated (44.9 times).

Subcellular distributions of NSE and MCE in strains of T. castaneum are given in Table 2. Esterase activities are found in all fractions, especially in microsomal pellet and supernatant fractions. In the two strains the cytosolic fraction (S) contained the greatest amount $(55.5 \pm 6.2 \%$ and $67.5 \pm 8.3 \%)$ of MCE activity. The distribution of $\mathrm{MCE}$ is the same between the resistant and the susceptible strain.

\subsection{Purification of $M C E$}

The elution profiles obtained by the different chromatographic techniques used were identical for the two strains. Data for the purification procedure are presented in Table 3. Approximately $19 \mu g$ and $23 \mu g$ of purified MCEs, respectively, from the resistant strain and the susceptible one were obtained from $35 \mathrm{~g}$ fresh weight of insects. The purification factor approached 1,521-1,774 fold and the yield was $0.038-0.045 \%$ of total protein. The purification procedure, involving sequential chromatography on gel filtration, ion exchange, hydroxyapatite columns, preparative isoelectric focusing and preparative native electrophoresis is efficient as indicated by the homogeneous band obtained for pure MCE (Fig. 2 and Table 3).

\subsection{Isoelectric focusing and molecular weight estimation}

The isoelectric point of purified MCE was significantly higher in the resistant strain $(\mathrm{p} I=7.3 \pm 0.2)$ than in the susceptible strain ( $\mathrm{p} I=6.6 \pm 0.1)$ (Student's $t$-test, $P=0.003$ ). The monomeric $\mathrm{M} r$ of the purified enzyme estimated by SDS-PAGE did not differ significantly between the resistant strain and the susceptible one (Student's $t$-test, $P$ $=0.253)$. The $\mathrm{Mr}$ estimated by gel filtration chromatography for susceptible and resistant MCE were, respectively, $62,000 \pm 2100$ and $61,700 \pm 1800 \mathrm{Da}$. This data supports the hypothesis that the native form of this carboxylesterase is monomeric (Fig. 3).

\subsection{Determination of kinetic constants}


The $K_{m}$ and $V_{m}$ values for malathion and for $\alpha$-naphthyl acetate were determined from Lineweaver-Burk plots and linear regression (Table 4). Based on kinetic values, MCE differs significantly between the two strains. The Michaelis constant $\left(K_{\mathrm{m}}\right)$ and the maximal velocity $V_{m}$ indicate that the rate of reaction of MCE is different between the resistant and the susceptible strain of $T$. castaneum. The MCE of the resistant strain has a $K_{m} 17$ times greater and a $V_{m} 4.6$ times greater than MCE from the susceptible strain. The susceptible MCE hydrolysed $\alpha$-naphthyl acetate faster than resistant MCE. The MCE specificity for the two substrates studied, which is reflected in the term $k_{\text {cat }} / \mathrm{K}_{\mathrm{m}}$, showed that MCE from the susceptible strain preferred $\alpha$-naphthyl acetate over malathion; on the other hand, MCE from the resistant strain had a greater specificity for malathion compared to $\alpha$-naphthyl acetate.

\section{Discussion}

The carboxylesterase inhibitor (TPP) synergized the effect of malathion in the resistant strain, restoring susceptibility to malathion in the Prm strain. These results implied that the resistance is likely to be the malathion-specific type, involving increased levels of a malathion-degrading carboxylesterase. The synergist TPP blocks the production of malathion mono-acid in a resistant strain of $T$. castaneum and its it is therefore probable that the resistance is caused by carboxylesterase activity (Dyte and Rowlands, 1968; Price, 1984).

Carboxylesterases (EC 3.1.1.1.) catalyse the hydrolysis of a wide range of xenobiotic carboxyesters and aromatic amides and is involved in a major route for the detoxification and the activation of such compounds (Krueger et al., 1953; Hosokawa et al., 1987, 1990; Kett erman et al., 1992) and subsequently in insecticide resistance (Oppenoorth, 1985).

The most commonly observed change that has been linked to resistance development is the increased carboxylesterase activity (Raymond et al., 1986). The putative mechanism involves a gene amplification that results in an overproduction of an esterase in resistant insects (Mouches et al., 1986; Field et al., 1988). Kinetic properties of this esterase are similar in susceptible and resistant insects (Devonshire, 1977); the esterase hydrolyses insecticides very slowly, but in highly resistant strains the enzyme accounts for $12 \%$ of the total soluble protein (Mouches et al., 1986). The esterase abundance apparently protects the insects by binding and sequestering insecticides rather than by rapid hydrolysis.

Table 1 Resistance to several insecticides in strains of T. castaneum: Asm (susceptible), PRm (malathionspecific resistant)

\begin{tabular}{|c|c|c|c|c|c|c|c|c|c|c|c|c|c|}
\hline \multirow[t]{3}{*}{ Insecticides } & \multicolumn{13}{|c|}{ Strains } \\
\hline & \multicolumn{7}{|c|}{ PRm } & \multicolumn{6}{|c|}{ Asm } \\
\hline & $n^{\mathrm{a}}$ & Slope \pm se & $\mathrm{LC}_{50}{ }^{\mathrm{b}}$ & $\begin{array}{c}95 \% \\
\mathrm{CL}^{\mathrm{b}}\end{array}$ & $\chi^{2}$ & $\begin{array}{l}\mathrm{d} \\
\mathrm{f}\end{array}$ & $\mathrm{RF}_{50}{ }^{\mathrm{c}}$ & $n^{\mathrm{a}}$ & Slope \pm SE & $\mathrm{LC}_{50}{ }^{\mathrm{b}}$ & $\begin{array}{c}95 \% \\
\text { CL }\end{array}$ & $\chi^{2}$ & $\begin{array}{l}\mathrm{d} \\
\mathrm{f}\end{array}$ \\
\hline Malathion & $\begin{array}{c}10 \\
0\end{array}$ & $6.84 \pm 0.88$ & $\begin{array}{c}116.59 \\
9\end{array}$ & $\begin{array}{c}109.495 \\
- \\
126.848\end{array}$ & $\begin{array}{c}6.7 \\
1\end{array}$ & 5 & $\begin{array}{c}250 . \\
2\end{array}$ & $\begin{array}{c}10 \\
0\end{array}$ & $\begin{array}{c}16.14 \pm 4.0 \\
8\end{array}$ & $\begin{array}{c}0.45 \\
8\end{array}$ & $\begin{array}{c}0.256 \\
- \\
0.843\end{array}$ & $\begin{array}{c}0.0 \\
3\end{array}$ & 5 \\
\hline Malaoxon & $\begin{array}{c}10 \\
0\end{array}$ & $5.99 \pm 0.30$ & 8.154 & $\begin{array}{l}6.951- \\
9.372\end{array}$ & $\begin{array}{c}5.4 \\
3\end{array}$ & 8 & 13.1 & $\begin{array}{c}10 \\
0\end{array}$ & $\begin{array}{c}16.87 \pm 5.7 \\
7\end{array}$ & $\begin{array}{c}0.37 \\
4\end{array}$ & $\begin{array}{c}0.271 \\
- \\
0.434\end{array}$ & $\begin{array}{c}0.0 \\
5\end{array}$ & 5 \\
\hline Fenitrothion & $\begin{array}{c}10 \\
0\end{array}$ & $\begin{array}{c}32.21 \pm 2.4 \\
9\end{array}$ & 0.330 & $\begin{array}{l}0.261- \\
0.375\end{array}$ & $\begin{array}{c}0.7 \\
9\end{array}$ & 3 & 1.3 & $\begin{array}{c}10 \\
0\end{array}$ & $\begin{array}{c}38.64 \pm 0.5 \\
3\end{array}$ & $\begin{array}{c}0.25 \\
1\end{array}$ & $\begin{array}{c}0.167 \\
- \\
0.330\end{array}$ & $\begin{array}{c}6.6 \\
1\end{array}$ & 3 \\
\hline Pirimiphos-methyl & $\begin{array}{c}10 \\
0\end{array}$ & $\begin{array}{c}36.49 \pm 5.1 \\
2\end{array}$ & 0.074 & $\begin{array}{c}0.054- \\
0.123\end{array}$ & $\begin{array}{c}1.2 \\
3\end{array}$ & 2 & 1.8 & $\begin{array}{c}10 \\
0\end{array}$ & $\begin{array}{c}39.87 \pm 3.6 \\
2\end{array}$ & $\begin{array}{c}0.03 \\
9\end{array}$ & $\begin{array}{c}0.034 \\
- \\
0.044\end{array}$ & $\begin{array}{c}2.3 \\
5\end{array}$ & 3 \\
\hline DDT & $\begin{array}{c}10 \\
0\end{array}$ & $1.50 \pm 0.34$ & 1.158 & $\begin{array}{l}0.611- \\
1.459\end{array}$ & $\begin{array}{c}1.3 \\
5\end{array}$ & 4 & $<1.0$ & $\begin{array}{c}10 \\
0\end{array}$ & $1.23 \pm 0.45$ & $\begin{array}{c}1.61 \\
7\end{array}$ & $\begin{array}{c}1.361 \\
- \\
1.917\end{array}$ & $\begin{array}{c}0.3 \\
7\end{array}$ & 4 \\
\hline
\end{tabular}




\begin{tabular}{|c|c|c|c|c|c|c|c|c|c|c|c|c|c|}
\hline Deltamethrine & $\begin{array}{c}10 \\
0\end{array}$ & $0.88 \pm 0.22$ & 0.039 & $\begin{array}{c}0.024- \\
0.059\end{array}$ & $\begin{array}{c}0.8 \\
9\end{array}$ & 4 & 1.0 & $\begin{array}{c}10 \\
0\end{array}$ & $0.45 \pm 0.03$ & $\begin{array}{c}0.03 \\
9\end{array}$ & $\begin{array}{c}0.015 \\
- \\
0.049\end{array}$ & $\begin{array}{c}2.2 \\
2\end{array}$ & 4 \\
\hline$\underset{\mathrm{d}}{\operatorname{Malathion}+\mathrm{TPP}}(1: 5)$ & $\begin{array}{c}10 \\
0\end{array}$ & $4.74 \pm 0.34$ & 0.823 & $\begin{array}{c}0.749- \\
0.892\end{array}$ & $\begin{array}{c}2.1 \\
6\end{array}$ & 3 & 2.8 & $\begin{array}{c}10 \\
0\end{array}$ & $6.26 \pm 1.23$ & $\begin{array}{c}0.29 \\
5\end{array}$ & $\begin{array}{c}0.207 \\
- \\
0.448\end{array}$ & $\begin{array}{c}6.2 \\
7\end{array}$ & 4 \\
\hline Malathion $+\mathrm{PB}(1: 5)^{\mathrm{e}}$ & $\begin{array}{c}10 \\
0\end{array}$ & $5.43 \pm 0.54$ & $\begin{array}{c}109.15 \\
5\end{array}$ & $\begin{array}{l}96.095- \\
114.627\end{array}$ & $\begin{array}{c}8.6 \\
7\end{array}$ & 5 & $\begin{array}{c}197 . \\
3\end{array}$ & $\begin{array}{c}10 \\
0\end{array}$ & $8.76 \pm 2.21$ & $\begin{array}{c}0.55 \\
2\end{array}$ & $\begin{array}{c}0.207 \\
- \\
1.035\end{array}$ & $\begin{array}{c}0.2 \\
2\end{array}$ & 4 \\
\hline $\begin{array}{l}\text { Malathion+DEM } \\
(1: 5)^{\mathrm{f}}\end{array}$ & $\begin{array}{c}10 \\
0\end{array}$ & $7.09 \pm 1.01$ & $\begin{array}{c}121.14 \\
0\end{array}$ & $\begin{array}{c}100.197 \\
- \\
131.685\end{array}$ & $\begin{array}{c}4.2 \\
0\end{array}$ & 4 & $\begin{array}{c}247 . \\
5\end{array}$ & $\begin{array}{c}10 \\
0\end{array}$ & $9.87 \pm 054$ & $\begin{array}{c}0.48 \\
8\end{array}$ & $\begin{array}{c}0.409 \\
- \\
0.576\end{array}$ & $\begin{array}{c}1.0 \\
4\end{array}$ & 6 \\
\hline
\end{tabular}

${ }^{\mathrm{a}}$ Sample size per dose.

${ }^{\mathrm{b}} \mathrm{LC}_{50}$ and $95 \%$ confidence limits are expressed in $\mathrm{mg} /$ paper.

${ }^{\mathrm{c}}$ Resistance factor 50.

d TPP=triphenyl phosphate

e $\mathrm{PB}=$ pyperonyl butoxide.

${ }^{\mathrm{f}} \mathrm{DEM}=$ diethyl maleate.
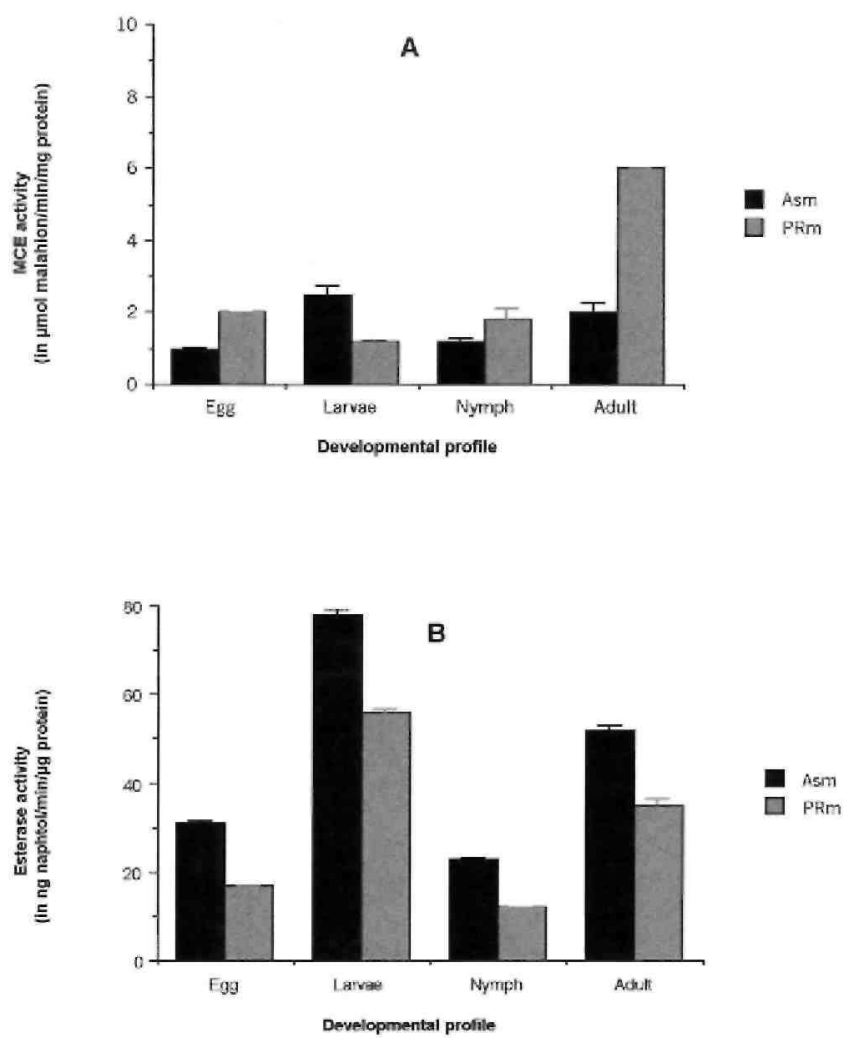

Fig. 1. Specific activity of MCE (A) and NSE (B) in a malathion-specific resistant (PRm) and a susceptible (Asm) strain of Tribolium castaneum during ontogenesis. The results represent the mean \pm standard error from four separate replicates.

In contrast, resistance to malathion has been attributed in some insects to enhance degradation by carboxylesterases, which hydrolyze the insecticide to less toxic and more easily excreted malathion monocarboxylic and dicarboxylic acids. Several examples of esterase-mediated malathion resistance involve increased activity of a specific carboxylesterase commonly referred to as the malathion carboxylesterase (MCE). These esterases have been implicated in malathion resistance of several strains of mosquitoes (Ziegler et al., 1987; Whyard et al., 1994a, 1995), houseflies (Oppenoorth and Van Asperen, 1960), blowflies (Whyard et al., 1994b), moths (Beeman et al., 1982), pteromalid parasitoids (Baker et al., 1998) and beetles (Price, 1984; Spencer et al., 1998).

As reported in various Tribolium strains, the naphthylesterase activity was much more active in the susceptible strain than in the malathion resistant strain (Wool et al., 1982; Mackness et al., 1983). By contrast, esterases 
from Musca domestica have been purified and appear to be active against both $\alpha$-naphthyl acetate and malathion (Kao et al., 1985). Moreover, in Nephottex cincticeps, malathion hydrolysing activity was elevated in the resistant strain and coincided with the electrophoretic band stained for hydrolysis of naphthyl ester (Miyata and Saito, 1976).

In most of the cases, although the MCE activity is high, authors observe a low activity towards other substrates including $\alpha$-naphthyl acetate. Oppenoorth and Van Asperen (1960) correlate the resistance of some strains of housefly to organophosphate pesticides with a failure of total esterase activity. They postulate a mutation in the wild type housefly gene responsible for esterase activity. This mutation results in the production of detoxifying hydrolase which loses total esterase activity. Reduced esterase activity toward naphthyl esters is a general phenomenon among malathion resistant populations of Plodia interpunctella (Beeman et al., 1982), Lucilia cuprina (Parker et al., 1991) and Tribol-ium castaneum (Mackness et al., 1983).

Table 2 Intercellular distribution of MCE and esterase in a malathion-specific resistant (PRm) and a susceptible (Asm) Tribolium castaneum strain. Insects were homogenised and differential centrifuged to obtained nuclear $(N)$, mitochondrial (Mi), microsomal (M) and supernatant (S) fractions. The enzyme distributions are shown as the total enzyme activity found in the fraction divided by the amount of protein in the fraction (relative specific activity). NSE=non specific esterase; $M C E=$ malathion carboxylesterase; $S A=$ specific activity and TA=total activity percentage. Recoveries of enzymes activities over homogenates were ranged from 87 to $104 \%$

\begin{tabular}{|c|c|c|c|c|c|}
\hline \multirow[t]{2}{*}{ Fractions } & \multirow[t]{2}{*}{ Strains } & \multicolumn{2}{|c|}{ NSE activity } & \multicolumn{2}{|c|}{ MCE activity } \\
\hline & & $\begin{array}{c}\mathrm{SA}(\text { in } \mu \mathrm{g} \\
\text { naphtol } / \mathrm{min} . / \mu \mathrm{g})\end{array}$ & TA(in \%) & $\begin{array}{c}\mathrm{SA}(\text { in } \mathrm{ng} \\
\text { malathion } / \mathrm{min} . / \mu \mathrm{g})\end{array}$ & $\mathrm{TA}($ in $\%)$ \\
\hline \multirow{2}{*}{ Crude homogenate } & PRm & $251.2 \pm 7.4$ & - & $1032.2 \pm 132.4$ & - \\
\hline & Asm & $339.1 \pm 19.3$ & - & $23.4 \pm 9.5$ & - \\
\hline \multirow{2}{*}{$1,500 \mathrm{~g}(\mathrm{~N}$ pellet $)$} & $P R m$ & $144.6 \pm 31.2$ & $8.1 \pm 1.3$ & $485.3 \pm 100.3$ & $12.4 \pm 0.9$ \\
\hline & Asm & $253.6 \pm 24.1$ & $3.2 \pm 0.3$ & $34.2 \pm 2.0$ & $9.9 \pm 1.4$ \\
\hline \multirow{2}{*}{$10,000 \boldsymbol{g}$ (Mi pellet) } & $P R m$ & $329.7 \pm 8.6$ & $10.3 \pm 2.7$ & $2346.1 \pm 45.6$ & $14.6 \pm 1.3$ \\
\hline & Asm & $389.4 \pm 7.7$ & $7.2 \pm 1.2$ & $54.8 \pm 7.5$ & $8.8 \pm 0.2$ \\
\hline \multirow{2}{*}{$100,000 \mathrm{~g}$ (M pellet) } & $P R m$ & $176.3 \pm 6.7$ & $23.4 \pm 4.3$ & $2745.5 \pm 176.0$ & $18.5 \pm 2.5$ \\
\hline & Asm & $279.1 \pm 4.5$ & $28.3 \pm 6.7$ & $87.4 \pm 13.4$ & $13.8 \pm 1.7$ \\
\hline \multirow{2}{*}{$\begin{array}{l}100,000 \boldsymbol{g}(\mathrm{S} \\
\text { supernatant })\end{array}$} & $P R m$ & $281.5 \pm 29.1$ & $58.2 \pm 3.4$ & $4,356.2 \pm 223.1$ & $55.5 \pm 6.2$ \\
\hline & Asm & $658.2 \pm 13.9$ & $61.3 \pm 6.3$ & $67.4 \pm 23.4$ & $67.5 \pm 8.3$ \\
\hline
\end{tabular}

The MCE was localized predominantly in the cytosol, with identical distributions in the resistant and in the susceptible strain, as reported in the blowflies (Whyard et al., 1994a). The intracellular distribution of MCE has only been examined in a few insects. In houseflies MCE was localized primarily in the microsomes (Kao et al., 1985), in green rice leafhoppers it was found in the cyto-sol (Motoyama et al., 1984), and in Culex tarsalis MCE was localized in the mitochondria of resistant insects and in the cytosol of susceptible ones (Whyard et al., 1994b). 
In our study, MCE was purified from the resistant and the susceptible strains. Their molecular weight is similar, ranging from 55 to $70 \mathrm{kDa}$ for many esterases (Heymann, 1980). Esterases with similar molecular weights have been reported in Boophilus microplus (De Jersey et al., 1985), Myzus persicae (Field et al., 1988), Culex quinquefasciastus (Merryweather et al., 1990),

Culex tarsalis (Whyard et al., 1994b) and Lucilia cupri-nia (Whyard et al., 1994a). However, the $\mathrm{p} I$ values of this protein were basic and differed significantly between the two strains. The p/values of these esterases are basic and are in the same region as those of esterases conferring malathion resistance in Drosophila melanogaster (Ashour et al., 1987), Culex pipiens (Whyard et al., 1994b). A difference concerning the level of glycosyl-ation of the protein may be one reason for the change in electrophoretic mobility and $\mathrm{p} I$, so it is possible that the susceptible and resistant MCEs are coded by the same gene (Small and Hemingway, 2000).

Kinetic studies suggest that (a) the MCE purified from our malathion-specific resistant strain of T. castaneum degrades malathion quickly than carboxylesterase of susceptible insects and that (b) this enzyme possess more affinity for malathion than for naphthyl esters, based on the $k_{c a t} / K_{m}$.

Table 3 Purification of MCE from a malathion-specific resistant Tribolium castaneum. The values represent averages from four separate replicates

\begin{tabular}{|c|c|c|c|c|}
\hline Fraction & Total protein (in mg) & $\begin{array}{l}\text { Specific activity (in nmol } \\
\text { malathion/min./mg } \\
\text { protein) }\end{array}$ & $\begin{array}{l}\text { Purification (- } \\
\text { fold) }\end{array}$ & $\begin{array}{l}\text { Recovery } \\
\text { (in } \% \text { ) }\end{array}$ \\
\hline $10.000 \mathrm{~g}$ supernatant & $5,640.12 \pm 234.41$ & $0.07 \pm 0.02$ & - & 100.00 \\
\hline $100.000 \mathrm{~g}$ supernatant & $5,050.27 \pm 37.55$ & $0.08 \pm 0.03$ & 1.14 & 102.33 \\
\hline $\begin{array}{l}\text { Sulfate ammonium } \\
\text { precipitation }\end{array}$ & $2,231.33 \pm 42.11$ & $0.18 \pm 0.03$ & 2.57 & 101.72 \\
\hline $\begin{array}{l}\text { Gel filtration (G25 } \\
\text { Sephadex) }\end{array}$ & $1,876.12 \pm 12.64$ & $0.17 \pm 0.02$ & 2.42 & 80.78 \\
\hline $\begin{array}{c}\text { Gel filtration (G200 } \\
\text { Sephadex) }\end{array}$ & $239.48 \pm 23.61$ & $1.16 \pm 0.08$ & 16.57 & 70.21 \\
\hline $\begin{array}{c}\text { Ion exchange } \\
\text { chromatography }\end{array}$ & $83.33 \pm 10.78$ & $1.92 \pm 0.24$ & 27.43 & 40.37 \\
\hline $\begin{array}{l}\text { Hydroxyapatite } \\
\text { chromatography }\end{array}$ & $5.40 \pm 1.54$ & $23.65 \pm 0.76$ & 333.86 & 32.21 \\
\hline Preparative isofocalisation & $1.03 \pm 0.47$ & $76.49 \pm 10.49$ & 1092.71 & 19.98 \\
\hline $\begin{array}{c}\text { Preparative PAGE } \\
\text { electrophoresis }\end{array}$ & $0.01 \pm 0.01$ & $124.21 \pm 7.77$ & 1774.43 & 0.38 \\
\hline
\end{tabular}

In Culex tarsalis, malathion resistance is known to be associated with a structurally unique MCE not found in the susceptible insect. This novel MCE enzyme is very low with $0.02 \%$ of total soluble protein and has a high turnover rate of $17 \mathrm{~min}^{-1}$ for malathion (Whyard et al., 1995). Malathion resistance in L. cuprina is also conferred by increased MCE activity. An MCE enzyme from a resistant strain has been purified and characterized. This esterase shows similarities with the MCE enzyme from resistant Culex tarsalis as it is also not abundant $(0.05 \%)$ and is a highly efficient catalyst with a turnover of 46 min-1 for malathion (Whyard et al., 1994b). Smyth et al. (1996) showed that MCE is also present in a susceptible strain of L. curprina; they suggest that the MCE activity in the malathion-specific resistant strain is structurally different from those in the 
susceptible strain.

According to the "mutant aliesterase" theory (Oppenoorth and Van Asperen, 1960), this type of resistance arises by a qualitative mutation at an esterase gene locus, resulting in the biosynthesis of a "mutant" enzyme. The mutant esterase has an altered substrate specificity, including enhanced activity toward the insec ticide ester bond, but decreased activity toward other substrates such as $\alpha$-naphthyl acetate (Newcomb et al., 1997).

Using direct assays for the degradation of malathion, our results have been interpreted as a change in esterase

specificity according to "the mutant aliesterase hypothesis" (Oppenoorth and Van Asperen, 1960; Newcomb et al., 1997). MCE has arisen by qualitative modifications in the susceptible MCE gene, enhancing the rate of malathion hydrolysis coupled with a reduced affinity for naphthyl ester substrates. 


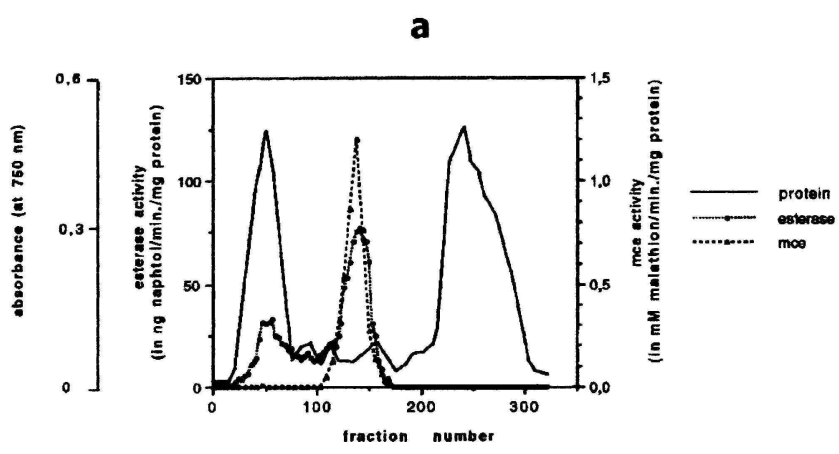

b
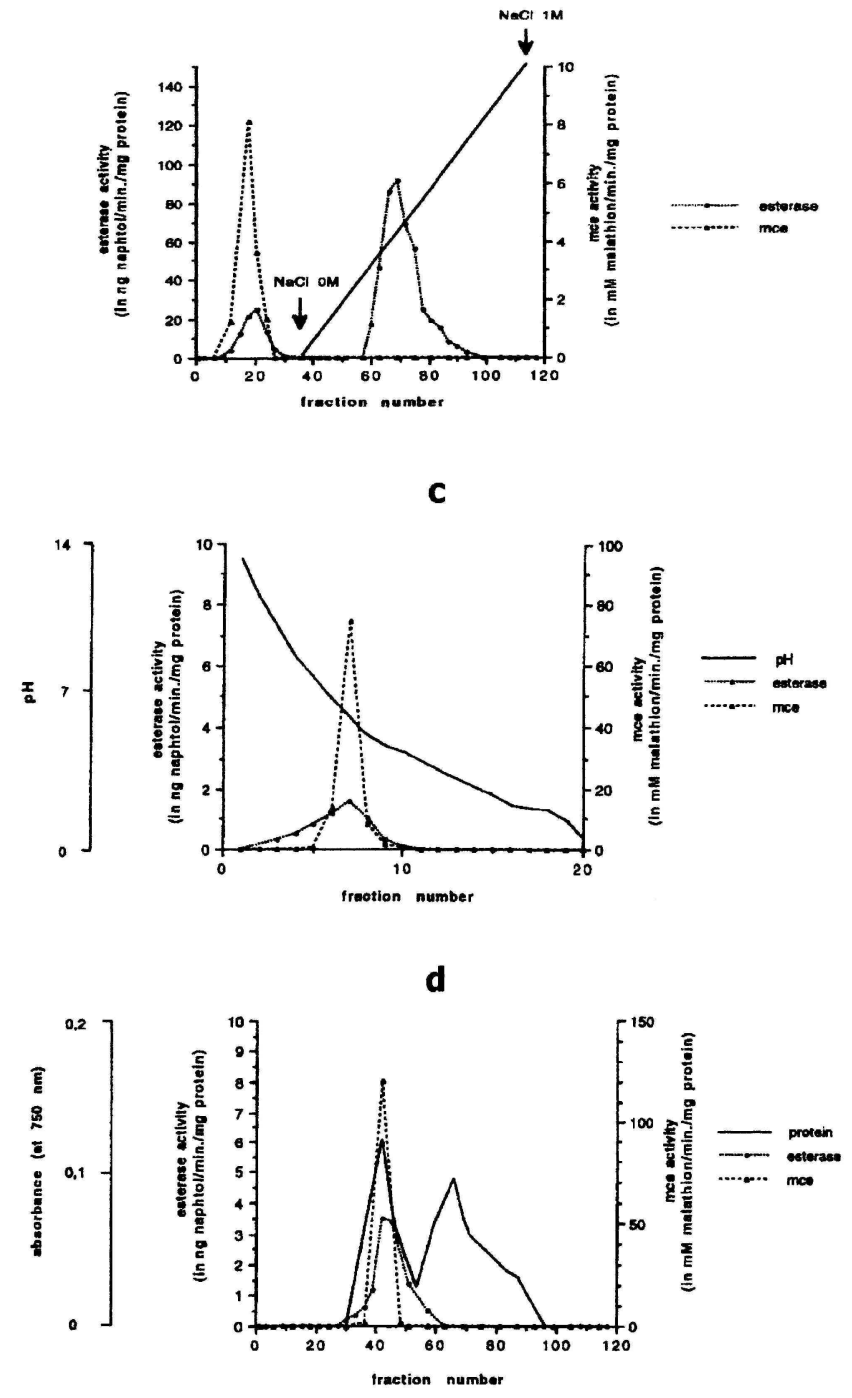

Fig. 2. Purification of resistant MCE and non-specific esterase (NSE) from malathion-specific resistant strain of Tribolium castaneum by successive preparative isofocalisation and PAGE electrophoresis. (a) Elu-tion profile of Sephadex G-200 gel filtration chromatography; (b) elu-tion profile of DEAE-fractogel ion exchange chromatography from gel filtration; (c) elution profile of hydroxyapatite-purified MCE from the preparative isofocalisation; (d) elution profile of preparative isofocalis-ation-purified MCE from the preparative PAGE electrophoresis. 


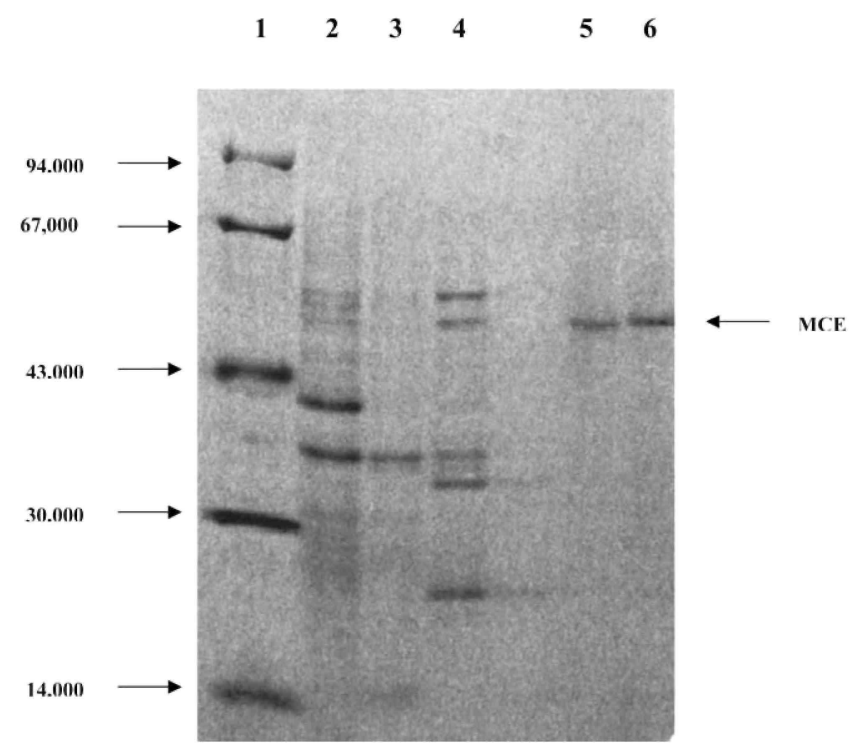

Fig. 3. SDS/PAGE analysis of various of steps from purification of MCE from a malathion-specific resistant and a susceptible Tribolium castaneum strain. Lane 1, molecular-mass markers; lane 2, resistant insects homogenate; lane 3, dialysed fractions after Sephadex G-200 gel filtration chromatography; lane 4, pooled fractions after DEAE-fractogel ion exchange chromatography; lane 5, peak activity from resistant strain after preparative electrophoresis chromatography; lane 6, peak activity from susceptible strain after preparative electrophoresis chromatography. The standard proteins used and their molecular weights were: phosphorylase (94,000), bovine serum albumin (67,000), ovalbumin (43,000), carbonic anhydrase $(30,000)$ and $(14,000)$. Stain is $0.2 \%$ Coomassie brilliant-blue in $45 \%(v / v)$ methanol $/ 5 \%(v / v)$ acetic acid, followed by destaining in $45 \%$ methanol/5\% acetic acid.

Table 4 Kinetic characterization of MCE from a susceptible (Asm) and a mala-thion-specific resistant (PRm) strains of Tribolium castaneum using malathion and $\alpha$-naphthyl acetate as substrates. The values represent the means and standard errors from three replicates

\begin{tabular}{|c|c|c|c|}
\hline Kinetic parameters & Strains & $\alpha$-Naphthyl acetate & Malathion \\
\hline \multirow{2}{*}{$K_{\mathrm{m}}($ in $\mu \mathrm{M})$} & $P R m$ & $0.101 \pm 0.012$ & $1.510 \pm 0.670$ \\
\hline & Asm & $0.014 \pm 0.003$ & $26.400 \pm 4.510$ \\
\hline \multirow{2}{*}{$\begin{array}{l}V_{\max }(\text { in } \\
\mu \mathrm{M} / \mathrm{min} . / \mathrm{mg})\end{array}$} & $P R m$ & $0.035 \pm 0.025$ & $0.242 \pm 0.025$ \\
\hline & Asm & $0.235 \pm 0.013$ & $0.052 \pm 0.031$ \\
\hline \multirow{2}{*}{$k_{\text {cat }}\left(\right.$ in $\left.\min .{ }^{-1}\right)$} & $P R m$ & 1.800 & 13.000 \\
\hline & Asm & 12.100 & 2.800 \\
\hline \multirow[t]{2}{*}{$k_{c \mathrm{at}} / K_{m}\left(\right.$ in $\left.\min .{ }^{-1} 1 \mathrm{x} \mu \mathrm{M}^{-1} 1\right)$} & $P R m$ & 66.500 & 8.600 \\
\hline & Asm & 864.200 & 0.100 \\
\hline
\end{tabular}

To summarize our results and conclusions concerning T. castaneum esterases, a protein band has been identified which is present in resistant and susceptible strains of $T$. castaneum at a low concentration. The evidence suggests that this protein is implicated in malathion-spe-cific resistance in the red flour beetle. Work is currently underway to investigate this possibility and any changes in expression or sequence of MCE from susceptible and 
Published in : Insect Biochemistry and Molecular Biology (2002), vol.32, iss. 9, p. 1181-1191

Status : Postprint (Author's version)

malathion-specific resistant T. castaneum.

\section{Acknowledgements}

The authors are thankful to Dr R. Feyereisen for helpful discussions and to J.-C. Gilson for technical support. The constructive comments by two anonymous reviewers on an earlier version of the manuscript are also gratefully acknowledged. This work was supported by a "Tournesol" grant from the CGRI (Belgium) and the INSERM (France). L. Arnaud is a postdoctoral researcher of the FNRS (Fonds National de la Recherche scientifique).

\section{References}

Ashour, M.B.A., Harshman, L.G., Hammock, B.D., 1987. Malathion toxicity and carboxylesterase activity in Drosophila melanogaster. Pest. Biochem. Physiol. 29, 97-111.

Baker, J.E., Fabrick, J.A., Zhu, K.Y., 1998. Characterization of ester-ases in malathion-resistant and suceptible strains of pteromalid parasitoid Anisopteromalus calandrae. Insect Biochem. Mol. Biol. 28, 1039-1050.

Beeman, R.W., Nanis, S.M., 1986. Malathion resistance alleles and their fitness in the red flour beetle (Coleoptera : Tenebrionidae). Journal of Economic Entomology 79, 580-587.

Beeman, R.W., Speirs, W.E., Schmidt, B.A., 1982. Malathion resistance in Indianmeal Moths infesting stored corn and wheat in the North Central United States. J. Econ. Entomol. 75, 950-954.

Champ, B.R., Dyte, C.E., 1976. Report of the FAO global survey of pesticides susceptibility of stored grain pests. Food and Agriculture Organization of the United Nations, Plant Production and Protection, series no. 5, FAO Rome, 297 pp.

Devonshire, A.L., 1977. The properties of a carboxylesterase from the peach-potato aphid Myzus persicae and its role in conferring insecticide resistance. Biochem. J. 167, 675-683.

De Jersey, J., Nolan, J., Davey, P., Riddles, P.W., 1985. Pestic. Biochem. Physiol. 23, 349-357.

Dyte, C.E., Rowlands, D.G., 1968. The metabolism and synergism of malathion in resistant and susceptible strains of Tribolium cas-taneum. J. Stored Prod. Res. 4, 157-173.

Field, L.M., Devonshire, A.L., Forde, B.G., 1988. Molecular evidence that insecticide resistance in peach-potato aphids results from amplification of an esterase gene. Biochem. J. 251, 309-312.

Heymann, E., 1980. Carboxylesterases and amidases. In: Jakoby, W. (Ed.), Enzymatic Basis of Detoxication, vol. II. Academic Press, New York, pp. 291-323.

Hosokawa, M., Maki, T., Satoh, T., 1987. Multiplicity and regulation of hepatic microsomal carboxylesterases in rats. Molecular Pharmacology 31, 579-584.

Hosokawa, M., Maki, T., Satoh, T., 1990. Characterization of molecular species of liver microsomal carboxylesterases of several animal species and humans. Arch. Biochem. and Biophys. 277, 219-227.

Kao, L.R., Motoyama, N., Dauterman, W.C., 1985. The purification and characterization from insecticide resistant and susceptible houseflies. Pest. Biochem. Physiol. 23, 228-238.

Ketterman, A.J., Jayawardena, K.G.I., Hemingway, J., 1992. Purification and characterization of a carboxylesterase involved in insecticide resistance from the mosquito Culex quinquefasciatus. Biochem. J. 287 , $355-360$

Lowry, O.H., Rosebrough, N.J., Farr, A.L., Randall, R.J., 1951. Protein measurement with the foiln phenol reagent. J. Biol. Chem. 193, 265-270.

Mackness, M.I., Walker, C.H., Rowlands, G.M., Price, N.R., 1983. Esterase activity in homogenates of 3 strains of Tribolium cas-taneum. Comp. Biochem. Physiol. 74c, 65-68. 
March, R.B., Fukuto, T.R., Metcalf, R.L., Maxon, M., 1956. Fate of ${ }^{32}$ P-labelled malathion in the laying hen, white mouse and American cockroach. J. Econ. Entomol. 49, 185-194.

Motoyama, N., Kao, L.R., Lin, P.T., Dauterman, W.C., 1984. Dual role of esterases in insecticide resistance in the green rice leafhopper. Pestic. Biochem. Physiol. 21, 139-148.

Mouches, C, Pasteur, N., Berge, J.B., Hyrien, O., Raymond, M., Vincent, B.R.S., Silvestri, M., Georghiou, G.P., 1986. Amplification of an esterase gene is responsible for insecticide resistance in a California Culex mosquito. Science 233, 778-782.

Matthews, W.A., 1980. A study of the fate of malathion in two strains of Rhyzopertha dominica. Pest. Biochem. Physiol. 13, 303-312.

Merryweather, A., Crampton, J.M., Townson, H, 1990. Purification and properties of an esterase from organophosphate-resistant strain of the mosquito Culex quinquefaciatus. Biochem. J. 266, 83-90.

Miyata, T., Saito, T., 1976. Mechanism of malathion resistance in the green rice leafhopper. J. Pest. Sci. 1, 2327.

Newcomb, R.D., Campbell, P.M., Ollis, D.L., Cheah, E., Russell, R.J., Oakeshott, J.G., 1997. A single amino acid substitution converts a carboxylesterase to an organophosphorus hydrolase and confers insecticide resistance on a bowfly. Proc. Natl. Acad. Sci. USA 94, 7464-7468.

Oppenoorth, F.J., Van Asperen, K., 1960. Allelic genes in the housefly producing modified enzymes that cause organophosphate resistance. Science 132, 298-299.

Oppenoorth, F.J., 1985. Biochemistry and genetics of insecticide resistance. In: Kerkut, G.A., Gilbert, L.I. (Eds.), Comprehensive insect physiology biochemistry and pharmacology, vol. 12. Pergamon, Oxford, pp. 731733.

Parker, A.G., Russell, R.J., Delves, A.C., Oakeshott, J.G., 1991. Biochemistry and physiology of esterases in organophosphate-suscep-tible and -resistant strains of the Australian Sheep Blowfly Lucilia cuprina. Pest. Biochem. Physiol. 41, 305-318.

Price, N.R., 1984. Carboxylesterase degradation of malathion in vitro by susceptible and resistant strains of Tribolium castaneum (Coleoptera: Tenebrionidae). Comp. Biochem. Physiol. 77, 95-98.

Raymond, M., 1993. PROBIT CNRS-UMII. Licence L93019. Avenix G. Prato and A. Ratsira, 34680 St. George d'Orques, France.

Raymond, M., Fournier, D., Bride, J.-M., Cuany, A., Berge, J., Mag-nin, M., Pasteur, N., 1986. Identification of resistance mechanisms in Culex pipiens (Diptera: Culicidae) from Southern France: insensitive acetylcholinesterase and detoxifying oxidases. J. Econ. Entomol. 79, 1452-1458.

Small, G.I., Hemingway, J., 2000. Differential glycosylation produces heterogeneity in elevated esterases associated with insecticide

resistance in the brown planthopper Nilaparvata lugens. Insect Biochemistry and Molecular Biology 30, 443453.

Smyth, K.-A., Walker, V.K., Russell, R., Oakeshott, J.G., 1996. Biochemical and physiological differences in the malathion carboxyle-sterase activities of malathion-susceptible and -resistant lines of sheep blowfly, Lucilia cuprina. Pest. Biochem. Physiol. 54, 48-55.

Spencer, A.G., Price, N.R., Callaghan, A., 1998. Malathion-specific resistance in a strain of the rust red grain beetle Cryptolestes ferrug-ineus. Bull. Res. Entomol. 88, 199-206.

Walter, C.M., Price, N.R., 1989. The uptake and penetration of pirim-iphos-methyl into susceptible and resistant strains of Tribolium cas-taneum. Comp. Biochem. Physiol. 94c, 419-423. 
Published in : Insect Biochemistry and Molecular Biology (2002), vol.32, iss. 9, p. 1181-1191

Status : Postprint (Author's version)

Wool, D., Noiman, S., Manheim, O., Cohen, E., 1982. Malathion resistance in Tribolium strains and their hybrids: inheritance pat-

terns and possible enzymatic mechanisms (Coleoptera: Tenebrionidae). Biochemical Genetics 20, 621-636.

Whyard, S., Russell, R.J., Walker, V.K., 1994a. Insecticide resistance and malathion carboxylesterase in Lucilia cuprina. Biochem. Genet. 32, 9-24.

Whyard, S., Downe, A.E.R., Walker, V.K., 1994b. Isolation of an esterase conferring insecticide resistance in the mosquito Culex tar-salis. Insect Biochem. Molec. Biol. 24, 819-827.

Whyard, S., Downe, A.E.R., Walker, V.K., 1995. Characterization of a novel esterase conferring insecticide resistance in the mosquito Culex tarsalis. Arch. Insect Biochem. Physiol. 29, 329-342.

Ziegler, R., Whyard, S., Downe, A.E.R., Wyatt, G.R., Walker, V.K., 1987. General esterase, malathion carboxylesterase and malathion resistance in Culex tarsalis. Pest. Biochem. Physiol. 28, 213-225. 